\title{
PRIMEIRA REPÚBLICA EM PERNAMBUCO: flagelos da representação política (1904-1911)
}

\author{
Audenice Alves dos Santos Zacarias*
}

\begin{abstract}
RESUMO: o presente artigo analisa a governança eleitoral e o rompimento do domínio da mais poderosa oligarquia de Pernambuco na Primeira República. Na historiografia nacional foi solidificada a interpretação de que, entre 1889 e 1930, as oligarquias regionais eram mantidas no poder pela prática da fraude, o controle sobre o voto do eleitor e a hegemonia política dos partidos republicanos. Neste trabalho ratificamos tal percepção evidenciando a escolha do Congresso Federal em recusar a judicialização como tentativa para legitimar o ritual eleitoral. Deste modo, nem mesmo a inédita participação ativa de eleitores e marginalizados do direito do voto na eleição pernambucana de 1911, que resultou na queda da oligarquia Rosa e Silva, foi capaz de prover a reconfiguração necessária no sistema representativo do novo regime.
\end{abstract}

PALAVRAS-CHAVE: Primeira República; Oligarquia; Pernambuco.

\section{First republic in Pernambuco: scourges of political representation (1904-1911)}

ABSTRACT: The present article analyses the electoral governance and the breking of Pernambuco's First Republic most powerful oligarchy domain. In the national historiography the interpretation was solidified that, between 1889 and 1930, the regional oligarchies were kept in power by the fraud pratice, the control over the electors vote and the political hegemony of the republican parties. In this work we confirm this perception evidencing the Federal Congress choice in refusing the judicialization as an attempt to legitimize the electoral ritual. In this way, not even the unpublished active participation of electors and the excluded from voting rights in Pernambuco's election of 1911, which resulted in the fall of Rosa e Silva oligarchy. It was able to provide the necessary reconfiguration in representative system of the new political regime.

KEYWORDS: First Republic; Oligarchy; Pernambuco.

\section{Primera república en Pernambuco: flagelos de la representación política (1904-1911)}

RESUMEN: El presente artículo analiza la gobernanza electoral y el rompimento del domínio de la más poderosa oligarquía de Pernambuco em la Primeira República. El la historiografia nacional se solidificó la interpretación de que, entre 1889 y 1930, las oligarquias regionales eran mantenidas en el poder por la práctica del fraude, el control sobre el voto del elector y la hegemonia política de los partidos republicanos. En este trabajo ratificamos tal percepción evidenciando la elección del Congresso Federal em rechazar la judicialización como intento para legitimar el ritual electoral. De este modo, ni siquiera la inédita participación activa de electores y marginados del derecho del voto en la elección pernambucana de 1911, que resultó en la caída de la oligarquía Rosa e Silva, fue capaz de proveer la reconfiguración necesaria en el sistema representativo del nuevo régimen PALABRAS CLAVE: Primeira República; Oligarquía; Pernambuco.

*Doutora em História pela Universidade Federal de Pernambuco. Atualmente é professora de História da rede estadual de ensino na Escola Vidal de Negreiros. Contato: Rua Bezerra da Palma, s/n, Afogados, CEP: 50770690, Recife-PE, Brasil. Email: audenicealves@yahoo.com.br. ORCID: http://orcid.org/0000-0001-7281-0473. 


\section{Introdução}

Em seu artigo inicial, a Carta Magna de 1891 declarou que "a Nação brasileira" passava a adotar como forma de Governo o regime representativo. Ainda assim, o voto universal para intervenção autorizada do povo no Estado, o deslocamento da verificação de poderes a um personagem alheio às rotinas políticas e o sistema proporcional para representação partidária nunca foram marcas da Primeira República por diversas e entrelaçadas razões.

Primeiramente, era claro o descompasso entre o texto constitucional e a realidade normativa, social, político e partidária nacional. Isto porque o proclamado respeito aos direitos políticos e individuais dos cidadãos brasileiros não se traduziu em mecanismos eleitorais para gerar eficácia social e efetivação da soberania popular. Do mesmo modo, a prometida representação das minorias não encontrou amparo no conjunto de regras e instituições que organizava as corridas eleitorais e muito menos na conjunção em que tais competições políticas ocorriam. Não fosse o bastante as variáveis sócias e econômicas serem abertamente utilizadas pelos poderosos locais para interferir desde o início do processo de votação, coexistia o agravo da ausência de partidos políticos nacionais, organizações programáticas ou ideológicas que organizassem o movimento republicano. Um desajuste regimental que fomentava nos atores políticos extremo desânimo em participar de jogos eleitorais desprovidos da necessária transparência, justiça, credibilidade do resultado final ou expectativa de que, a cada partida, todos teriam iguais condições de acesso ao poder. Ao contrário, a descentralização de poder e a autonomia normativa nos membros federados se tornaram instrumentos à implantação de um sistema representativo consolidador do poder às oligarquias regionais.

Como terceiro ponto a ser ressaltado, em sentido inverso ao exposto anteriormente, a premissa constitucional que legava ao Legislativo "declarar lei específica sobre casos de incompatibilidade eleitoral" e fazer "verificação e reconhecimento dos poderes de seus membros"1 não apenas foi imediatamente realizada como continuamente resguardada por servir ao corpo político para decidir as eleições e, com isto, arrefecer os impedimentos à governabilidade dos que estavam no poder.

Num cenário de degeneração política, onde acordos tecidos no Congresso eram tão efêmeros como os padrões que orientavam as decisões das facções partidárias, o Poder Central muitas vezes se via impossibilitado de costurar maioria sólida para aprovação de sua agenda. Como "alternativa única”, o presidente Manuel Alberto Campos Sales confeccionou 
aliança peculiar entre Executivo e Legislativo no pacto conhecido como "política dos governadores"2. Por volta de 1898, a Câmara dos Deputados altera seu regimento interno visando confirmar que, após as eleições, somente fossem reconhecidos pela Casa candidatos indicados pelos governadores e que estivessem nivelados ao entendimento dos coronéis e oligarcas de sua região. Por sua vez, estes influentes locais tinham a fiança do Governo Central de que seu amplo poder seria respeitado enquanto ofertassem ao presidente da República incondicional e irrestrito apoio no âmbito parlamentar. Deste modo, se o sistema político do Império fora marcado pelo centralismo do Poder Moderador, a Primeira República via ascender um sistema federalista de Presidencialismo forte amalgamado a um Poder Legislativo sem qualquer comprometimento em elevar a arquitetura eleitoral ao nível percebido nas mais destacadas civilizações liberais do século XX.

Como bem sabiam os congressistas, existia duas possíveis orientações à administração dos processos eleitorais: a verificação dos poderes (comandada pelo Legislativo) e o jurisdicional (conferindo ao Judiciário desde a qualificação dos eleitores, a recepção e apuração dos votos e a diplomação dos candidatos vencedores). Na Inglaterra, até 1868, era permitido à Câmara dos Comuns as condições de evocar o controle sobre a verificação dos poderes e a validação dos diplomas de seus membros como símbolo da própria independência. Contudo, em 1896, para impedir que o Parlamento desvirtuasse o processo eleitoral com formas facciosas, o Primeiro-Ministro inglês Benjamin Disraeli sancionou a lei que completou a transferência ao Judiciário do controle sobre o processo eleitoral, dando origem à Justiça Eleitoral. Enquanto isso no Brasil deu-se o processo inverso.

No Período Colonial, juízes ordinários e juízes-de-fora cooperavam nas fases de qualificação dos eleitores, apuração dos votos e proclamação dos resultados. Já no Império, visando moralizar as eleições, a lei eleitoral de 1881 criou barreias às fraudes pela implementação do voto direto e retirada da função de alistamento das Juntas Paroquiais de Qualificação para conduzi-las aos juízes de paz, juízes municipais e juízes de direito. $\mathrm{Na}$ República, contudo, a elite política brasileira escolheu não apenas ratificar o aprisionamento da governança eleitoral republicana à discricionariedade típica dos tribunais políticos como impôs forte retração da participação da magistratura na burocracia eleitoral desde as primeiras normatizações eleitorais.

Desde a primeira lei eleitoral republicana do Brasil, as etapas iniciais dos escrutínios (alistamento para concessão do título eleitoral, divisão do município em seções, definição de locais de votação, eleição dos membros das mesas eleitorais, votação em si, contagem primária dos votos e produção das atas que seguiriam às juntas apuradoras) se desenvolveriam 
na unidade territorial imediatamente inferior ao distrito, ou seja, os municípios ${ }^{3}$. Afinal, era justamente nos municípios onde coronéis e oligarquia, como chefes da política imediata, arregimentavam apoio ao Poder Central e aos governadores em troca de maior liberdade para impor suas vontades na máquina pública.

Em Pernambuco, desde a saída do capitão florianista Alexandre José Barbosa Lima do Executivo estadual, no ano de 1896, as relações de poder que impuseram eram geridas pelo oligarca Francisco de Assis da Rosa e Silva e seu Partido Republicano. Com hábitos polidos, adquiridos nos longos períodos que passava na Europa, Rosa e Silva cuidava pessoalmente para garantir contínuas vitórias dos candidatos situacionistas, a ocupação dos postos oficiais por seus correligionários e a fidelidade das municipalidades à rede política majoritária. Porém, como político de longa jornada ${ }^{4}$, não demorou a perceber que a crise iminente no alquebrado sistema político brasileiro conferia necessária abertura à diversidade de opinião no Parlamento.

Tendo como ponto central o cuidado de não alterar as bases que abonavam as relações de poder estabelecidas, a Câmara Federal toma por discurso público a preocupação de “atender aos anseios da nação para moralização política”. Assim, entre 1902 e 1903, os parlamentares se voltam à análise do projeto de reforma eleitoral exposto pelo Deputado Anísio Auto de Abreu como "necessidade rigorosa e absoluta de salvação da República"s.

Acompanhada diariamente pela imprensa nacional, a tramitação da citada matéria era aproveitada pelos congressistas para se fazerem apresentar como defensores de inovações que trouxessem avaliação positiva ao sistema político republicano. Contudo, não se acanhavam de explicitar total rejeição ao alargamento das condições para competitividade dos grupos políticos minoritários, recusar maior participação da massa popular e protelar a judicialização política. Entretanto, mesmo não estando em curso no país qualquer ativismo específico ou proativo para reinterpretação constitucional que conduzisse à retração do Poder Legislativo e maximização da interferência do Judiciário no andamento das eleições, pela primeira vez, os órgãos de comunicação escrita transcreveram aos leitores discurso de um congressista em defesa de maior participação da magistratura no processo eleitoral.

Não negando temer "desgraça-lo ao sujeita-lo a imensos dessabores", o Deputado Francisco Belarmino argumentava sobre a "enorme contribuição que a retidão do Judiciário poderia trazer à administração do processo eleitoral”. Indo além, o deputado mineiro sugeriu a criação de uma "magistratura especial nos estados, com funcionários nomeados pelo presidente da República, mas, no dia seguinte, tornar-se-iam independentes para fazer alistamento, escolher mesas eleitorais e estabelecer apuração. Como se as espumas das 
agitações eleitorais não existissem, trabalhariam para proclamar a todo o país os votos dos escrutínios". No entanto, rapidamente o Deputado Germano Hasslocher fez coro à maioria dos congressistas contrários à tendência percebida em outras sociedades por judicializar o processo eleitoral. Explicando seu ato como "cuidado constitucional" e "empenho de proteger os servidores do Judiciário da politicagem republicana"6, a Câmara rejeita a proposta e encerra as discussões pela implantação de uma Justiça Eleitoral naquele momento.

Sem contar com apoio de seus pares e sendo duramente criticado pela imprensa, que considerava o projeto original de reforma eleitoral "uma verdadeira manta de retalhos e incapaz de superar os vícios originários"7, o Deputado Anísio de Abreu professou aceitar que "a reforma eleitoral estava morta". Indignado, ratifica a percepção comum sobre o "completo desinteresse dos congressistas em facilitar o alistamento, dificultar as fraudes e anular o suicídio em que se constituiu a política dos governadores" $"$.

Todavia, é preciso salientar que, antes de ser posto em discussão na Câmara o projeto do Deputado Anísio de Abreu, o jovem periódico Correio da Manhã já tinha delegado "aos pés do grande estadista Francisco Rosa e Silva a esperança de ver melhorado o processo eleitoral". E não seria este o único órgão da imprensa a fazer tal aposta. Segundo a revista carioca O Malho, "o conselheiro do Norte era o único singularmente apto não apenas para purificar o sistema eleitoral, mas todo o aparelho político-administrativo mal construído desde 15 de novembro e mal remendado de lá para cá"19. E no âmbito parlamentar, o Deputado Anísio de Abreu professou que "mesmo nem sempre estando de acordo com o conselheiro Rosa e Silva, não podia negar que este é um dos mais ilustres Senadores e que está aparelhado para o embate regenerador das eleições”. Sendo assim, Anísio de Abreu se declarava pronto para atuar como "soldado às ordens vindas do ilustre Senador pernambucano na campanha patriótica da regeneração do processo eleitoral"’ (grifos nossos).

Entre 1903 e 1904, tramitou na Câmara Alta os trabalhos em torno da reforma eleitoral, competindo a Rosa e Silva o dilema de atender aos grupos distintos com seu texto substitutivo. Aos que, assim como ele, tinham se beneficiado da corrompida rotina eleitoral não chocou o fato de constatar a cristalização do divórcio entre representação e justiça. $\mathrm{Na}$ margem oposta, segundo a Gazeta de Notícias, populares se dirigiam diariamente ao Senado Federal confiando que "o político de maior prestígio do momento utilizaria sua eloquência para articular boas leis contra os maus costumes políticos”. A estes, de algum modo, Rosa e Silva procurou atender às expectativas com significativas inovações quanto aos critérios de alistamento, de modalidade de voto, de representação das minorias e de singelo aceno ao Judiciário. Como passaremos a analisar. 
Desde as primeiras leis e decretos eleitorais da República, o cadastramento dos eleitores era realizado por "subcomissões seccionais" em que os serventuários da justiça se limitavam a atuar como "escrivães das atas". Na prática, admitia-se aos mandatários municipais manipular a etapa inicial do processo eleitoral pela criação de comissões unanimes. Um escândalo vergonhoso que levava alguns órgãos da imprensa nacional a jocosamente rotular o alistamento eleitoral como "verdadeira buceta de Pandora"10. Justificando a necessidade de "garantir imparcialidade no processo de qualificação eleitoral", o Senador Rosa e Silva fez aprovar duas importantes novidades. Pela primeira vez, haveria regulamento único de alistamento dos eleitores para os sufrágios federais, estaduais e municipais. Igualmente inovador no texto proposto pelo Senador pernambucano era o recadastramento ao qual estavam compelidos os eleitores de todo o país. Ainda mais importante, tal ação seria feita por uma única comissão especial obrigatoriamente presidida por um juiz de direito da comarca, "ou quem suas vezes fizesse”. Aliado a isto, era exigido que para se tornar eleitor o cidadão precisava fazer o requerimento pessoalmente. Tais alterações na etapa inicial do processo eleitoral são consideradas por Jairo Nicolau como "as mais importantes da nova lei por terem acabado com o alistamento ex-officio" ${ }^{11}$. No entanto, até este momento, não era possível confirmar plenamente tal assertiva. Isto porque "o único documento oficial da época com informações sobre todos os municípios brasileiros é o relatório 'Estatístico eleitoral da República dos Estados Unidos do Brasil', publicado pelo Ministério da Agricultura, Indústria e Comércio, em 1914" e o mesmo possui como corte temporal os anos de 1905 a 1912, inviabilizando a realização de um comparativo entre o número de alistados antes e depois da Lei Eleitoral Rosa e Silva. Visando atender tal demanda, o presente artigo expõe inédito levantamento das variações no quadro eleitoral por município em Pernambuco antes e depois da referida lei (ver tabela 1). O que nos permite afiançar forte retração no número de eleitores considerados aptos ao direito do voto neste estado.

Outra questão fundamental era demonstrar como o último estágio do processo eleitoral, rotulado por terceiro escrutínio ou "verificação de poderes", fora preservado na reforma. Como justificativa para tal empenho, o legislador Rosa e Silva aduzia que, “diferentemente do Império, onde existia maior confiança sobre alistamentos reais e atas eleitorais verdadeiras, na República as comissões de verificação de poderes e o plenário congressual são necessários para atuar como filtros no Parlamento"12. Desta forma, "o equilíbrio formal encontrado por Campos Salles, em 1899, via reforma regimental, era estendido ao âmbito dos próprios escrutínios, fazendo-se previsto na lei eleitoral"13. 
Porém, consciente da necessidade de emitir algum sinal de evolução nas preocupações eleitorais, Rosa e Silva promove "o principal episódio de reforma do voto na Primeira República"14. Superando os desacordos entre parlamentares quanto às modalidades do voto e possibilidades de representação das minorias, o Senador pernambucano conseguiu ver aprovada a permissão para o eleitor votar secretamente ou de forma aberta, assim como poderia acumular seus votos em um só candidato. Não fosse o bastante, todos as redes partidárias, inclusive as majoritárias, eram obrigadas a lançar lista incompleta de candidatos às vagas em disputa, consentindo aos grupos minoritários reais condições de vitória de um ou dois de seus nomes.

Antes mesmo de sua promulgação, em 15 de novembro de 1904, a Lei Eleitoral 1.269, mais conhecida como Lei Eleitoral Rosa e Silva, foi saldada por diversos órgãos da imprensa como "regeneração do país ao ver encerradas as patocadas eleitorais, filhas das fraudes e da indiferença do povo, assim, satisfazendo uma das mais vivas e urgentes necessidades públicas" ${ }^{15}$. De tal modo que, ainda em nossos dias, a Lei Eleitoral Rosa e Silva está consagrada como "a mais importante lei eleitoral da Primeira República" ${ }^{\text {. }}$. Contudo, aos que tão fortemente exaltaram a nova lei, a maior apreensão era saber como se dariam os pleitos na terra do honrado Senador Rosa e Silva. E a oportunidade viera em 30 de janeiro de 1906, quando, cumprindo determinação federal, foi marcado o primeiro pleito sobre as diretrizes estabelecidas pela nova lei eleitoral.

Em Pernambuco, as expectativas eram diversas. Havia os que acreditavam "ver a leimilagre de Rosa e Silva faze-lo cair na própria armadilha"17. Ao Jornal Pequeno era impossível negar que "a lei Rosa e Silva estava realmente entrosada e tão bem-feita que iluda à primeira vista", porém, alertava que "um quinto da deputação do estado, reservada à oposição, é insuficiente para representar a minoria pela falta de proporção real”. Não fosse o bastante, "era preciso contar com a honestidade política e boa vontade do governo em cumprir a letra da lei". Assim, decretava que "da minoria, crente na ficção de ser governo, só sairá eleito o candidato conveniente à situação, pois se não pudesse garantir sempre o seu triunfo, o conselheiro Rosa e Silva não teria apoio à reforma. Deste modo, venha o que vier, Pernambuco é que será sempre a vítima"18. E o resultado final daquela eleição apenas ratificou o discurso do Jornal Pequeno, uma vez que, em nenhum momento, o domínio absoluto da oligarquia rosista foi ameaçado. Mas, procurado imprimir diferente interpretação aos resultados da lei Rosa e Silva, o Jornal do Recife declarou que, "a cada momento, a reforma eleitoral de 1904 opera modificações nos costumes eleitorais da nação. Muito em breve, as batalhas eleitorais terão força para chamar a atenção das massas pela certeza dada ao eleitor 
da importância de seu comparecimento às urnas" ${ }^{\prime 19}$. Poucos anos depois, na eleição pernambucana de 1911, a profecia do jornal situacionista se cumpriu, todavia, em sentido reverso ao esperado.

Motivada por questões econômicas e não apenas pelos maus costumes da classe política, a queda de uma das mais antipáticas, opressivas e longevas oligárquicas da Primeira República deixou o país em extrema apreensão e chamou a atenção da imprensa internacional sobre os perigos advindos do falacioso sistema político do Brasil.

A cada dia, comerciantes, ricos industriais e produtores agrícolas pernambucanos tomavam Rosa e Silva como símbolo do empobrecimento acentuado do Leão do Norte. Tal diagnóstico ocasionou a perda de apoio interno, imprescindível à rede oligárquica, e abriu a possibilidade de inédito acordo entre a elite e a oposição local. Porém, se nos pleitos anteriores nomes tradicionais da política pernambucana, como José Mariano, barão de Lucena, Henrique Millet, Gonçalves Maia e Martins Júnior, eram jocosamente rotulados como "legião de fantasmas"20, o mesmo não se deu quando este grupo resolve superar suas desavenças para apoiar um novo partido. Presidido por Lourenço de Sá, mas liderado pelo médico João Ribeiro de Brito, surge o Partido Republicano Conservador de Pernambuco como filial do PRC do Rio de Janeiro, agremiação a qual pertencia o então presidente da República, Marechal Hermes da Fonseca.

De modo inovador, o novo partido não apenas lança um militar em sua chapa como a comissão executiva do PRC “convida o povo pernambucano para juntos proclamar Dantas Barreto ao cargo de governador do Estado", ou, nas palavras dos colaboradores, ao posto de "salvador de sua terra" ${ }^{21}$. E mesmo que o ideário salvacionista não tenha sido abraçado por todos, a esperança de ver encerrado o domínio da oligarquia estadual arregimentou amplo apoio ao PRC. Figurando entre os mais ativos combatentes nomes fortes da elite econômica, a exemplo de Frederico João Lundgren; moços intelectuais, como Mário Mello, Trajano Chacon, Barreto Campelo; e até mesmo seguimentos sociais excluídos do direito do voto, como as mulheres deste estado.

Num período em que a política era aceita como atividade exclusivamente masculina, algumas pernambucanas decidiram atuar no teatro onde se desenrolavam as negociações políticas e sociais. Fazendo questão de esclarecer que estavam lutando "em nome da moralidade do glorioso estado de Pernambuco", aquelas mulheres tiveram positiva recepção no PRC. Não que estivesse nos planos da agremiação defender ideais sufragistas, mas sabia serem as mulheres um apoio preciso. Em Olinda, Recife, Jaboatão e diversos municípios do interior, foram criadas as "juntas femininas". Como imenso regozijo, por terem, enfim, um 
espaço onde poderiam debater os acontecimentos, expor dissensões, conseguir audição, formar e reformular opiniões e programar ações conjuntas, muitas delas pagavam para ver publicados nas páginas dos jornais o seu nome como o de suas companheiras de agremiação. E enquanto "as senhoras patrícias de Gravata, recolhiam assinaturas e esperavam novas adesões ao centro pró-Rosa e Silva"22, as impetuosas dantistas promoviam atividades coletivas, livres e plurais, acreditando que poderiam contribuir para restauração da vida política e social desta localidade. Às dezenas, saiam pelos bairros para doutrinar mocinhas a que se juntassem ao movimento político e para reforçar o apelo a Dantas Barreto para que o mesmo deixasse o Rio de Janeiro e desse início aos comícios do PRC em Pernambuco. E quando, finalmente, foi marcado o comício do candidato da oposição, as dantistas, patrocinadas pela Liga Comercial do Recife, vestiram roupas brancas e adornaram a cidade com fitas verdes e amarelas, deixando tudo pronto para o evento que reuniu cerca de 50 mil pessoas no centro da capital do estado ${ }^{23}$. Porém, o espírito festivo e democrático logo se encerrou.

Num encontro promovido pela Associação Comercial do Recife, o general Dantas Barreto acirrou os ânimos de seus apoiadores ao afirmar que "o direito é a garantia da ordem. Contudo, quando esta falha, o que temos é regressão e desordem. Então, a reação passa a ser a ordem" ${ }^{24}$. Tais palavras foram interpretadas como um aviso de que o militar somente aceitaria como resultado final do pleito a sua vitória. Em respondendo ao seu líder, o jornalista Trajano Chacon convidou "todos os pernambucanos dignos deste nome a dar provas de sua força na campanha pelo liberalismo e honra política"25. A partir de então, diversos comícios do PRC acabaram dando lugar a atos de violência. Isto porque, ao ouvirem o jingle de seu candidato ${ }^{26}$, os "vassouras", como ficaram conhecidos os dantistas que carregam a vassoura como símbolo de que iriam varrer a oligarquia do poder estadual, se envolviam em confrontos com policiais ou qualquer aliado rosista.

Quanto a Rosa e Silva, este somente deu início aos preparativos do Partido Republicano à campanha estadual em agosto de 1911. Afinal, como o sistema político republicano continuava permitindo os vícios correlatos ao coronelismo e os meios para fazer figurar nas mãos do governo local os postos-chave da administração pública, a vitória nas eleições, ainda que fraudulenta, parecia-lhe questão de tempo. Contudo, em poucos dias se viu obrigado a admitir surpresa pelo modo como "após breve estadia na Europa, o cenário estadual estava transformado" ${ }^{27}$.

Como nunca antes, era nítido o aguardo até fora do país sobre a luta eleitoral em Pernambuco no ano de $1911^{28}$. Afinal, em lugar dos fragmentados e facciosos grupos de 
oposição, a poderosa oligarquia rosista tinha de enfrentar Dantas Barreto, ex-ministro de Guerra do presidente da República, Marechal Hermes da Fonseca. E apesar de pouco conhecido da população local, o general ganhava, a cada dia, a simpatia da população. Impondo ao conselheiro Rosa e Silva necessidade de modificar suas estratégias.

Pela primeira vez em sua carreira política, o chefe do Partido Republicano precisou lançar seu próprio nome à vaga do Executivo em Pernambuco. E tendo ao seu dispor meios políticos para interferir no andamento da competição, convence o então governador, Herculano Bandeira de Melo, eleito pelo PR, a renunciar ao cargo, em 07 de setembro. Atitude igualmente solicita ao presidente do Senado Estadual, a quem caberia ocupar a vaga. Seguindo as normativas legais e, especialmente, a vontade do oligarca, a chefatura estadual foi entregue ao presidente da Câmara, Estácio de Albuquerque Coimbra. Este, imediatamente, publica decreto de antecipação das eleições. Isto porque, segundo a Carta Magna e a Lei Eleitoral de Pernambuco, "vagando, por qualquer motivo, o lugar de governo, o substituto legal mandará imediatamente proceder a nova eleição que se realizará impreterivelmente no sexagésimo dia após aquele em que tiver ocorrido a vaga" ${ }^{29}$. Deste modo, o pleito, anteriormente marcado para dezembro, se realizou em 05 de novembro de 1911, reduzindo o tempo dos dantistas para angariar votos.

No esperado dia da eleição, ambos os lados em disputa abusaram de atos violentos, deixando cidadãos feridos pelas bombas lançadas até dentro das seções eleitorais, impossibilitando a realização do pleito em alguns municípios. E como se não fosse o bastante, centenas de cangaceiros armados com bacamarte e vestidos com gibões de couro e talabartes de cartucho cruzando o peito, entraram em cena. Uma força oficiosa que, segundo o Diário de Pernambuco, fora contratada em Alagoas para servir aos agrupados na oposição. Já na versão dos dantistas, ratificada por imagens feitas pela imprensa internacional (ver Figura 1), os referidos senhores foram pagos para auxiliar a polícia estadual na repressão aos cidadãos partidários de Dantas Barreto.

O que nos chama a atenção é como, mais uma vez, as mulheres pernambucanas operam atos de enorme valentia. Com atuação digna de aplausos na imprensa do Distrito Federal, senhoras e senhoritas, sem auxílio de maridos ou filhos e sem deixar de manifestar sua feminilidade por meio de belas vestimentas e adornos, mostraram-se prontas para defender sua família e seu lar dos marginais que empestavam a cidade (ver Figura 2).

Independente do temor generalizado em todo estado, a participação do eleitorado e o amparo dos populares à chapa oposicionista foram sem precedente. Abrindo margem a que a Comissão Executiva do Partido Republicano Conservador de Pernambuco e a Liga do 


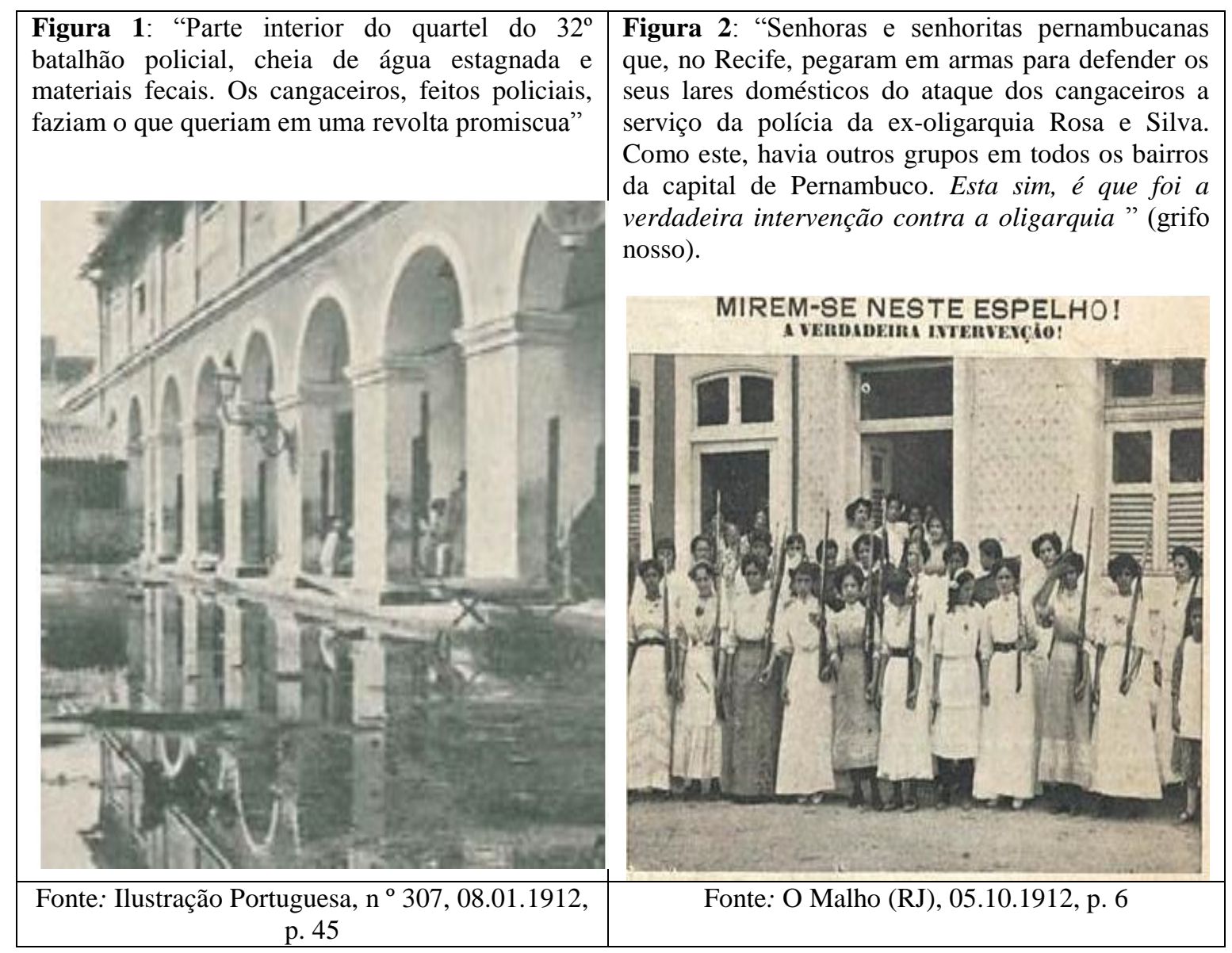

Comércio do Recife resolvessem operar levantamento paralelo dos votos. Contudo, se a "apuração alternativa" decretou a vitória do candidato do PRC, o Diário de Pernambuco, jornal pertencente a Rosa e Silva, reclamava a si o direito de "fonte oficial" do resultado das urnas. Sabendo possuir meios, legais e ilegítimos, para ver seu discurso confirmado pelo Congresso Estadual no ato de diplomação do novo governador, a folha situacionista testemunhava que, "mesmo com a inédita derrota nas cidades de Recife, Olinda e Jaboatão, sobreveio a Rosa e Silva honesto e brilhante sucesso. Dando prova das consciências livres, dos bons princípios e da habitual fidelidade de Pernambuco ao Partido Republicano" 30 . Um pronunciamento, no mínimo, que contribuiu ao deflagrar de gravíssima convulsão política e social, sobretudo, na capital. Isto porque, fortalecidos pela adesão de parte da elite econômica e pela ajuda de bases do Exército alojadas neste estado, os inimigos da oligarquia promoveram uma sequência de eventos inimagináveis.

Em primeiro lugar, como o Diário de Pernambuco sempre fora arma poderosa para inflacionar suposta mediocridade da oposição, forjar grandiosidade do oligarca e tecer discursos favoráveis à manutenção do $\mathrm{PR}$ no poder, o jornal rosista se tornou a primeira 
vítima da revolta. Por ironia, justamente os vendedores de jornais, que antes faziam circular o Diário pelas ruas da capital, passaram a compor um dos grupos mais temidos naquele momento (ver Figuras 3 e 4). E somente após a saída do conselheiro da posição de proprietário, em janeiro 1912, o Diário de Pernambuco voltou a circular livremente.

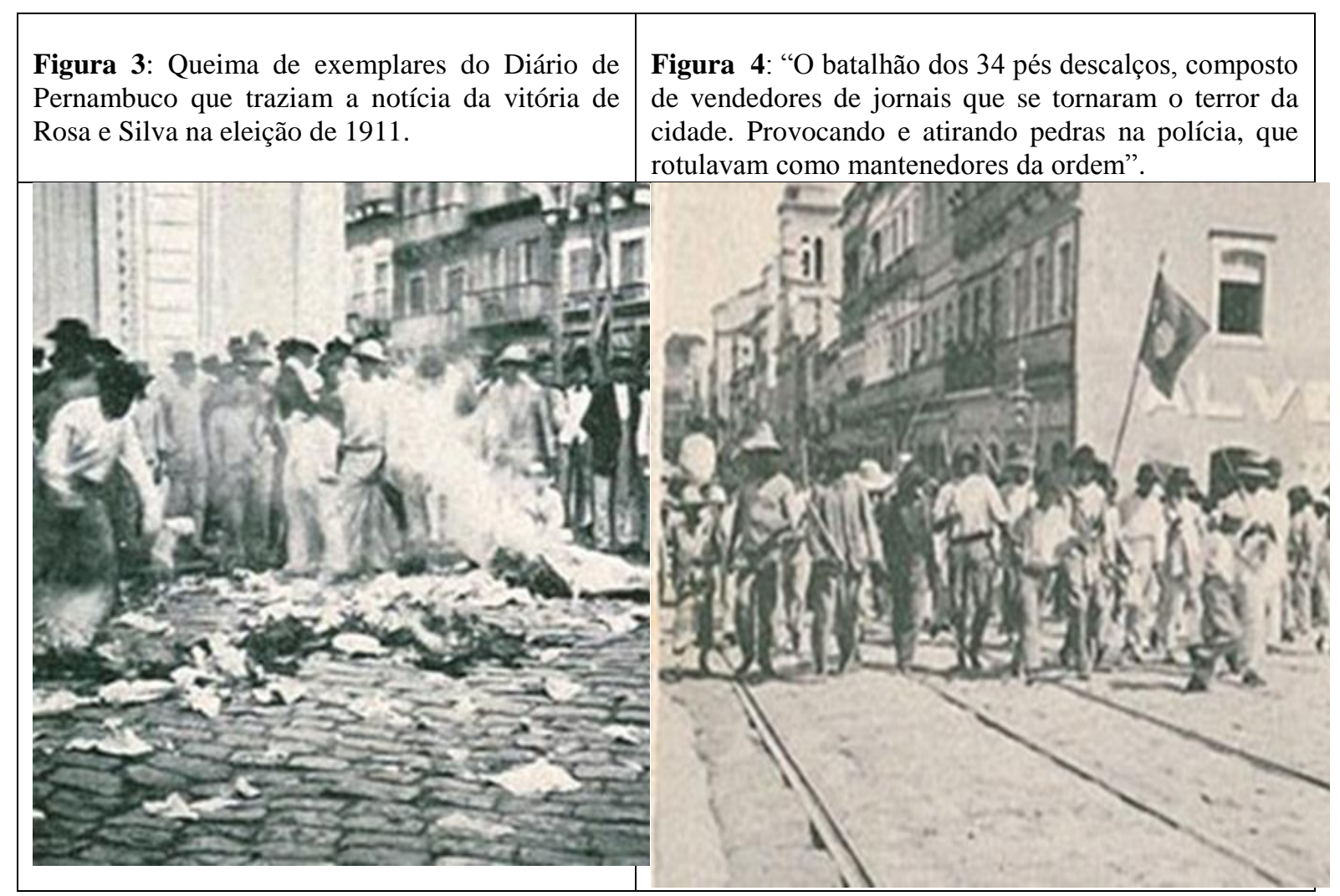

Fonte: Ilustração Portuguesa, n 307, 08.01.1912, p. 48

No ápice do confronto, ocorre o episódio que ficou conhecido como "a hecatombe da Boa Vista”. Em 10 de novembro de 1911, patrulhas do Exército deixaram o forte do Brum e o cais do Apolo para se juntar ao grupo que lançava rajadas de tiros na fachada norte do Palácio do Campo das Princesas. Obrigada ao sacrifício de defender o governo estadual, a força pública de segurança (que seria hoje a Polícia Militar) saiu para revide quando, ao passar pela ponte da Boa Vista, foi surpreendida por tiros vindos de embarcações postas no rio Capibaribe. E como se não lhes bastasse a morte, "os cadáveres dos soldados de polícia sofriam do populacho desenfreados e cruéis ultrajes"31. Por seu turno, os dantistas também amargaram algumas baixas. Exemplo disto, o farmacêutico Herculano Barbosa de Miranda "foi barbaramente assassinado pelas balas da famigerada e sanguinária polícia pernambucana" 32 (ver Figuras 5 a 7). 
Figura 5: "Alguns dos vários soldados da polícia mortos na hecatombe da Boa Vista".
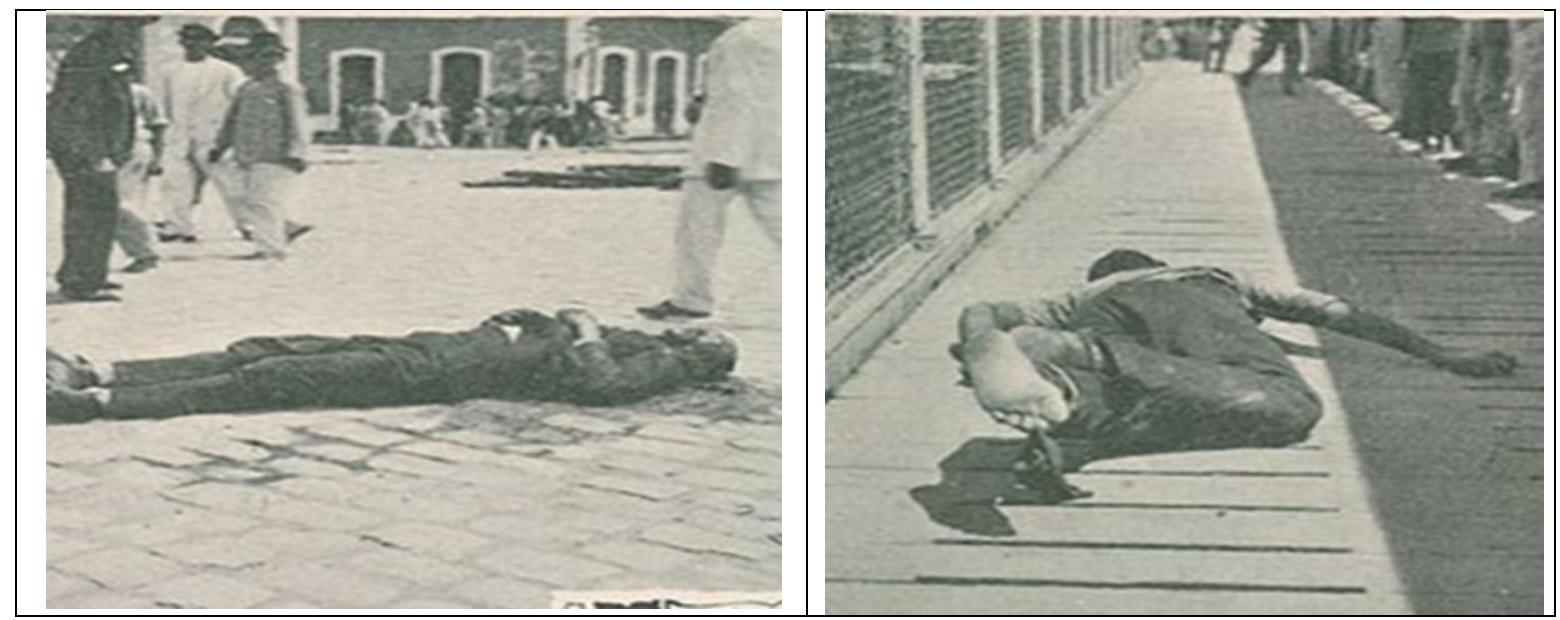

Fonte: Ilustração Portuguesa.

Figura 6: Prisão de Francisco Tavares, chefe de polícia do município de Vitória. Por onde o automóvel passava as vaias eram ininterruptas.

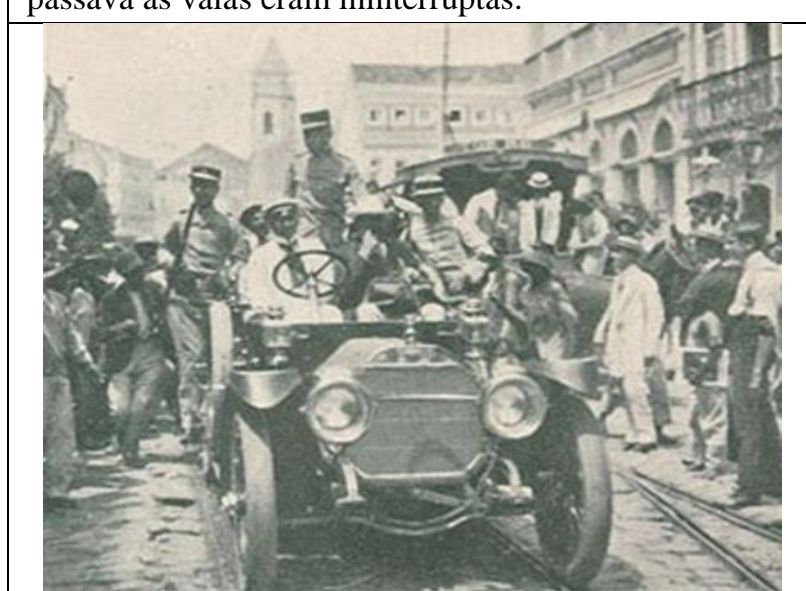

Fonte: Ilustração Portuguesa, $\mathrm{n}^{\circ}$ 307, 08.01.1912, p. 46 a 48.
Figura 7: Funeral de Herculano Barbosa de Miranda, morto polícia rosista de Pernambuco, em 1911

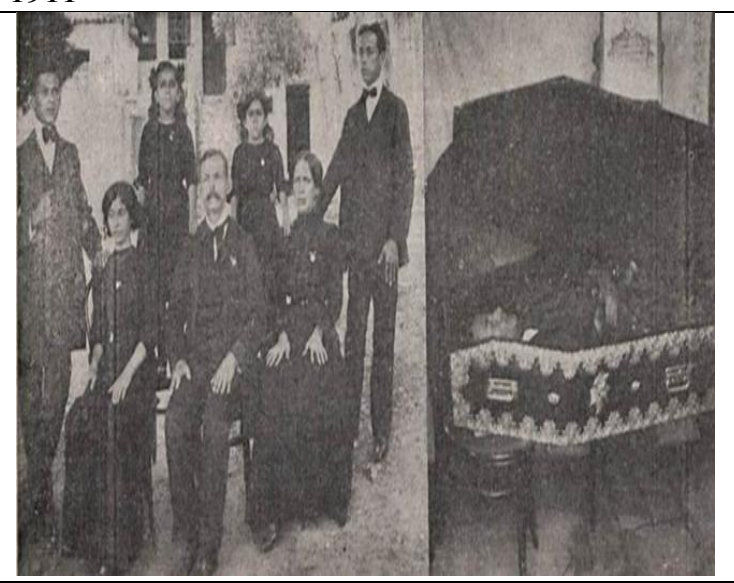

Fonte: O Malho (RJ), 17.02.1912, p. 22.

Atônito pelas perseguições, destruições e assassinatos que paralisaram o cotidiano em grande parte de Pernambuco, Estácio Coimbra inaugura o precedente constitucional que consentia a um membro federado requisitar intervenção do Governo Central ${ }^{33}$. Porém, divergindo do prometido, as forças da União deslocadas ao Recife eram abertamente contrárias ao governo oligárquico. Desta feita, sentindo o desmonte de sua estrutura de poder, em dezembro de 1911, o chefe do Executivo e vinte nove dos quarenta e dois parlamentares do Congresso Estadual se evadiram da capital pernambucana. Dentre estes, o primeiro secretário da Câmara dos Deputados e subchefe da polícia, Francisco de Assis Rosa e Silva Junior "que, tendo secundado o seu pai na direção da política situacionista, tomou por asilo a cidade de Lisboa. Quanto aos demais, ninguém soubera o destino"34. 
Coube, então, ao primeiro secretário da Câmara Alta Estadual, o Senador e Padre João da Costa Bezerra, convocar o Congresso Legislativo para cumprir seu papel. Em 12 de dezembro de 1911, os cinco senadores e oito deputados restantes se reuniram com intuito de estudar a procedência dos protestos, verificar atas, boletins e demais documentos pertinentes apresentados oficialmente para que, no dia 15 de dezembro, fosse emitida sumula final dos trabalhos. Como já esperado, o presidente do Senado de Pernambuco, Oswaldo Machado, declara, em sessão realizada a 16 de dezembro daquele ano, que a "comissão é de parecer que o general Emídio Dantas Barreto seja reconhecido e proclamado governador eleito para o quadriênio a iniciar-se em 1912”. No entanto, o mencionado parlamentar fez questão de justificar a atitude do Legislativo Estadual como “de pouco peso, uma vez que já estava decidido quem seria o futuro governador" ${ }^{\prime 2}$.

Quanto à reverberação internacional, é curioso perceber a imprensa portuguesa alertando não sobre questões da validade do regime político do Brasil, mas como "os aspectos trágicos da revolução popular abrirão um perigoso precedente" ${ }^{37}$. Uma interpretação parcialmente acompanhada por jornais cariocas ao afiançarem que "a reação contra as oligarquias se propagará aos outros estados"38. Uma consequência que, seguramente, não era desejada por vencidos e mesmo por parte dos vencedores. É o que podemos perceber na última reunião ministerial de 1911, quando o presidente Hermes da Fonseca declara publicamente o general Dantas Barreto governador eleito, ao mesmo tempo, ordena que fosse registrado em nota que "somente em Pernambuco a luta eleitoral efetuou-se em condições constrangedoras ao país"39.

No cenário pernambucano, após 1911, observamos uma explosão no quantitativo eleitoral (ver tabela 1) e o retorno ao Recife de antigos adversários políticos de Rosa e Silva. No entanto, os apoiadores do "salvacionismo dantista" logo se decepcionaram ao perceber que os escrutínios realizados nos tempos de Dantas Barreto não se diferenciavam dos acontecidos na vigência da oligarquia deposta. Prova disto, na eleição para renovação de um terço do Senado, ocorrida em 30 de janeiro de 1912, a situação utilizou "as mesmas práticas de perturbação da ordem e validação de atas falsas". Levando o Senador Francisco Glicério a solicitar ao Congresso Nacional que a comissão de verificação de poderes recusasse diplomar o dantista João Ribeiro de Brito, como Senador Federal, "sob pena de conspurcação do regime representativo" ${ }^{40}$. E até mesmo a imprensa que tão fortemente havia apoiado o general Dantas Barreto em 1911, confessava que "a República prefere se jogar no abismo a ser 'salva' pelos militares" (ver Figura 8). 
Figura 8: charge - "Há certos remédios que quando aplicados em doses diminutas, salvam o doente, mas em dose exagerada, matam!".

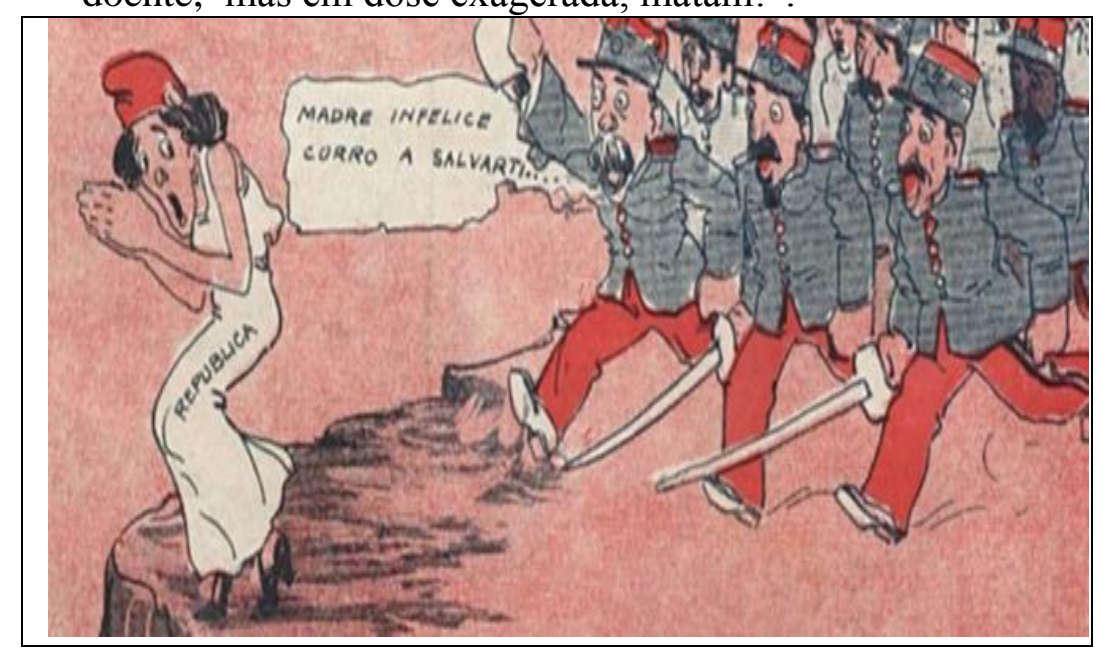

Fonte: O Malho (RJ), 30 de novembro de 1912, p. 15.

Mas, talvez nenhum outro prosélito da campanha de Dantas Barreto ao governo estadual tenha sofrido maior revés do que o jornalista Trajano Chacon. Nos primeiros anos da administração dantista, Chacon passou a fazer duras críticas aos excessos cometidos diretamente ou com consentimento do chefe do Executivo contra a oposição. Como resultado, em 11 de agosto de 1913, ao sair de um teatro na rua Imperatriz, o referido jornalista foi assassinado por policiais à paisana liderados pelo Coronel Francisco Melo, comandante da polícia fardada de Pernambuco. Mais grave ainda, os responsáveis "pelo monstruoso crime, que ficou no caminho do tirânico Dantas Barreto", foram absorvidos, em março de 1914, causando revolta dentro e fora de Pernambuco. Todavia, chamando-nos a atenção como, entre os ecos de indignação emitidos em âmbito nacional, a imprensa carioca anunciou que "Pernambuco estava novamente à espera de um gênio que venha libertá-lo do sanguinário domínio de Dantas Barreto" ${ }^{41}$ deixando clara a noção de perpetuo estado do povo brasileiro à espera por um "salvador da nação". Afinal, à elite política e intelectual da Primeira República a população brasileira não passava de "uma vasta congérie humana, acumulada nas cidades ou dispersa pelos campos e sertões, desplantada, seminômade, servilizada, sem pão, sem terras, sem vontade, sem consciência cívica", não podendo, assim, prescindir do "abrigo do governo dos mais capazes" ${ }^{\prime 2}$. Tal grave interpretação tinha como consequência a separação entre eleição e representação popular, bem com certa permissividade às práticas de fraudes vistas como "forçoso recurso" para evitar que chegasse "ao Congresso a borra mental da nação"43. Somente com o Código Eleitoral de 1932 se dera a evolução na questão representativa no Brasil pela introdução de garantias do voto feminino, do voto secreto, da proporcionalidade e 
da esperada criação da Justiça Eleitoral. E se todas as mazelas da República brasileira não foram resolvidas, ao menos abriu-se espaço para outras discussões.

\section{Conclusão}

Tendo como corte político-temporal o período compreendido entre a produção da Lei Eleitoral Rosa e Silva, de 1904, até a convulsiva eleição pernambucana de 1911, conseguimos avançar na compreensão sobre a querela do sistema político na Primeira República. Conforme evidenciado, aliados ou adversários da república oligárquica apresentavam igual entendimento de desconexão entre representação e justiça, representação e proporcionalidade, representação e democracia liberal com isonomia entre todos os cidadãos. E mesmo quando militares e grupos partidários aglutinaram entre seus apoiadores inúmeros populares, eleitores ou não, estes permaneciam sendo vistos como uma massa amorfa e terminantemente dependente da liderança de "homens mais capazes", sendo logo controlados e emudecidos por seus "salvadores".

Nas narrativas congressuais e extraparlamentares, durante as discussões pela reforma eleitoral de 1904 ou no decorrer do pleito pernambucano de 1911, a elite política e intelectual jamais tivera como objetivo um aperfeiçoamento da máquina eleitoral por avanços normativos que gerassem alternância no poder ou ampliação do sufrágio e agregação social permanente. Antes, para além da Primeira República, fora cristalizada a ideia de que, para alcançar estabilidade e melhorias profundas na vida política e ordinária do país, os cidadãos deveriam se submeter à liderança de um ente ou grupo "salvador". Uma compreensão que, mesmo com ressalvas, acreditamos finalmente estar em franco processo de transformação nos dias atuais do Brasil.

Tabela 1: Comparativo do quantitativo eleitoral por município em Pernambuco (1902-1912)

\begin{tabular}{|l|c|c|c|c|}
\hline Municípios & $\mathbf{1 9 0 2 - 1 9 0 3}$ & $\mathbf{1 9 0 5}$ & $\mathbf{1 9 1 1}$ & $\mathbf{1 9 1 2}$ \\
\hline Afogados Ingazeira & 926 & 498 & 573 & 696 \\
\hline Agua Preta & 1.400 & 776 & 1.066 & 1.265 \\
\hline Aguas Belas & 807 & 763 & 1.095 & 1.225 \\
\hline Alagoa de Baixo & 623 & 407 & 449 & 495 \\
\hline Altinho & 1.134 & 692 & 830 & 956 \\
\hline Amaraji & 785 & 530 & 995 & 1.097 \\
\hline Barreiros & 885 & 745 & 945 & 945 \\
\hline Belmonte & 411 & 406 & 515 & 592 \\
\hline
\end{tabular}


Continuação da Tabela 1

\begin{tabular}{|c|c|c|c|c|}
\hline Municípios & $1902-1903$ & 1905 & 1911 & 1912 \\
\hline Bezerros & 839 & 851 & 1.028 & 1.166 \\
\hline Boa Vista & 342 & 266 & 354 & 417 \\
\hline Bom Conselho & 1.067 & 839 & 772 & 1.251 \\
\hline Bom Jardim & 1.287 & 1.291 & 1.362 & 1.888 \\
\hline Bonito & 1.291 & 822 & 1.466 & 1.543 \\
\hline Brejo da M. de Deus & 1.483 & 1.380 & 1.524 & 1.700 \\
\hline Buíque & 1.395 & 562 & 789 & 942 \\
\hline Cabo & 778 & 770 & 1.135 & 1.133 \\
\hline Cabrobó & 578 & 271 & 421 & 521 \\
\hline Canhotinho & 990 & 1.011 & 1.785 & 1.785 \\
\hline Caruaru & 1.182 & 1.608 & 2.070 & 2.930 \\
\hline Correntes & 1.322 & 637 & 945 & 1.080 \\
\hline Escada & 767 & 567 & 736 & 893 \\
\hline Exu & - & - & 577 & 656 \\
\hline Flores - & - & 303 & 387 & 608 \\
\hline Floresta & 767 & 826 & 1.015 & 1.015 \\
\hline Gameleira & 964 & 835 & 998 & 1.515 \\
\hline Garanhuns & 1.055 & 1.691 & 2.190 & 2.557 \\
\hline Glória do Goitá & 860 & 565 & 645 & 721 \\
\hline Goiana & 1.863 & 1.560 & 1.771 & 1991 \\
\hline Granito & 804 & - & 356 & 439 \\
\hline Gravatá & 761 & 533 & 1.067 & 1.319 \\
\hline Igarassu & 631 & 775 & 942 & 1.037 \\
\hline Ipojuca & 817 & 656 & 884 & 884 \\
\hline Itambé & 665 & 402 & 588 & 698 \\
\hline Jaboatão & 1.275 & 886 & 1.183 & 1.118 \\
\hline Leopoldina & 502 & 323 & 511 & 558 \\
\hline Limoeiro & 778 & 904 & 1.055 & 1.407 \\
\hline Nazaré da Mata & 2.342 & 1.893 & 2.204 & 2.811 \\
\hline Olinda & 1.254 & 1.028 & 1.359 & 1.932 \\
\hline Ouricuri & 1.460 & 926 & 1.058 & 1.078 \\
\hline Palmares & 1.490 & 1.157 & 1.767 & 2.100 \\
\hline Panelas & 1.170 & 712 & 886 & 1.011 \\
\hline Paudalho & 1.215 & 665 & 1.116 & 1.248 \\
\hline Pedra & 367 & 488 & 588 & 578 \\
\hline Petrolina & 694 & 749 & 679 & 679 \\
\hline
\end{tabular}


Continuação da Tabela 1

\begin{tabular}{|l|c|c|c|c|}
\hline Municípios & $\mathbf{1 9 0 2 - 1 9 0 3}$ & $\mathbf{1 9 0 5}$ & $\mathbf{1 9 1 1}$ & $\mathbf{1 9 1 2}$ \\
\hline Quipapá & 1.400 & 773 & 1.114 & 1.281 \\
\hline Recife & - & 5.850 & 8.085 & 9.726 \\
\hline Rio Formoso & 783 & 522 & 715 & 788 \\
\hline Salgueiro & 609 & 485 & 750 & 750 \\
\hline São Bento & 829 & 546 & 710 & 710 \\
\hline São José do Egito & 1.054 & 553 & 628 & 733 \\
\hline São Lourenço & 874 & 591 & 1.267 & 1.467 \\
\hline Sirinhaém & 943 & 495 & 825 & 825 \\
\hline Tacaratu & 667 & 664 & 680 & 680 \\
\hline Taquaritinga & 1.125 & 705 & 1.077 & 1.113 \\
\hline Timbaúba & 907 & 930 & 965 & 1.400 \\
\hline Triunfo & 1.410 & 644 & 848 & 849 \\
\hline Vitória & 1.414 & 1.311 & 1.823 & 2.068 \\
\hline Vila bela & 801 & 508 & 766 & 805 \\
\hline TOTAL & $\mathbf{5 4 . 8 4 2}$ & $\mathbf{4 8 . 1 4 6}$ & $\mathbf{6 6 . 2 4 0}$ & $\mathbf{7 7 . 5 2 3}$ \\
\hline
\end{tabular}

Fonte: Pasta das Câmaras Municipais, CM 96-97 - APEJE

\section{Notas}

1 BRASIL, Constituição de 1891 , capítulo I, artigos $18^{\circ}$ e $27^{\circ}$.

2 Sobre o processo de construção do pacto Campos Sales, ler BACKES, Ana Luiza. "Fundamentos da republicana: repensando o pacto Campos Sales". Brasília: Senado Federal, 2006.

3 BRASIL, Lei n $\mathrm{n}^{\circ}$ 35, 26.01.1892.

4 Sobre o comando de Rosa e Silva em Pernambuco, ler ZACARIAS, Audenice Alves dos Santos: "A República oligárquica de Pernambuco: montagem e declínio do domínio de Francisco de Assis Rosa e Silva". Tese Doutorado, Universidade Federal de Pernambuco. Recife, 2017.

5 BRASIL, Anais da Câmara Federal, 14.05.1903, p. 389; 20.07.1903, p. 302.

6 BRASIL, Anais da Câmara Federal, 04.08.1903, p. 23.

7 O País (RJ), 18.08.1903.

8 BRASIL, Anais da Câmara Federal, 26.08.1903, p. 441.

9 Correio da Manhã (RJ), 27.12.1901; O Malho (RJ), 27.12.1902.

10 Gazeta de Notícias (RJ), 25.04.1904 e 30.09.1904.

11 NICOLAU, Jairo Marconi. Eleições no Brasil: do Império aos dias atuais. RJ: Zahar, 2012, p. 56.

12 BRASIL, Anais do Senado Federal, Francisco Rosa e Silva, 17.08.1904, p. 1483.

13 RICCI, Paolo. ZULINI, Jaqueline Porto. Quem ganhou as eleições? A validação dos resultados antes da criação da justiça eleitoral recebido em 13 de setembro de 2012. Revista Sociologia e Política. Curitiba, v. 21, n. 45, p. 91-105, mar. 2013, p. 97.

14 HOLANDA, Cristina Buarque de. Modos de representação política. O experimento da Primeira República brasileira. Belo Horizonte: Editora UFMG; Rio de Janeiro: Editora IUPERJ, 2009, p. 117.

15 Correio da Manhã (RJ), 08.11.1904.

16 HOLANDA, Cristina Buarque de. Op. cit., p. 132.

17 A Província (PE), 04.01.1906.

18 Jornal Pequeno (PE), 30.01.1906. 
19 Jornal do Recife (PE), 12.07.1907

20 Diário de Pernambuco (PE), 03.09.1902. Quanto a Martins Júnior, este faleceu em agosto de 1904.

21 Jornal Pequeno, 19.06.1911, p.3; A Província (PE), 08.08.1911.

22 Diário de Pernambuco (PE), 26.09.1911.

23 A Província (PE), 18 a 24.09.1911.

24 Diário de Pernambuco (PE), 18.08.1911.

25 A Província (PE), 14.10.1911, p. 2.

26 Utilizando a melodia composta por famosos artistas da época, Mariano e Zazá, a música "a vassoura" era ouvida ao final de todos os comícios dantistas proclamando tendo por refrão: "Pernambuco há vinte anos (bis) /Que vive escravizado /General Dantas Barreto (bis) /Vem salvar o nosso estado / Salvai, salvai Querido General /O nosso estado das mãos de um traidor”. Jornal Pequeno (PE), 25.03.1911, p. 4; A Província (PE), 01.05.1911, p. 2; Diário de Pernambuco (PE), 10.05.1911, p. 3.

27 Diário de Pernambuco (PE), 18.10.1911; 21.11.1911

28 A eleição pernambucana de 1911 foi notícia no jornal francês Le Figaro (26.11.1911, p.2). Indo além, a revista Ilustração Portuguesa, de Lisboa, enviou ao Recife correspondentes que nos deixaram importantíssimas imagens daquele pleito.

29 PERNAMBUCO, Constituição de 1891, artigo 61; PERNAMBUCO, Lei 797, artigo $12^{\circ} \S 2^{\circ}$.

30 Diário de Pernambuco (PE), 21 e 25.11.1911.

31 Mensagem do Governador Estácio Coimbra ao Congresso Estadual de Pernambuco, 28.11.1911.

32 A Província (PE), 30.11.1911, p. 4

33 BRASIL, Constituição de 1891, artigo $6^{\circ}, \S 3^{\circ}$ : “O governo federal não poderá intervir em negócio peculiares aos estados, salvo para estabelecer a ordem e tranquilidade nos estados, seguindo requisição dos respectivos governadores".

34 Ilustração Portuguesa, $n^{\circ} 307,08.01 .1912$, p. 46.

35 Jornal do Recife (PE), 14.12.1911; Jornal Pequeno (PE), 18.12.11911.

36 Ilustração Portuguesa, $\mathrm{n}^{\circ}$ 307, 08.01.1912, p. 41.

38 O Tempo (RJ), 15.12.1911.

39 Gazeta de Notícias (RJ), 18.11.1911, p. 2; Jornal do Recife (PE) 14.12.1911.

40Correio da Manhã (RJ), 03 de maio de 1912, p. 4; Anais da Câmara dos Deputados (RJ), 30.12.1913, p.667.

41Jornal do Comércio (RJ), 20.08.1913, p. 9; A Notícia (RJ), 15.08.1913.

42 VIANA, Oliveira. O idealismo da Constituição. São Paulo: Nacional, 1930, p. 60.

43AMADO, Gilberto. Eleição e representação. Rio de Janeiro: Oficina Industrial Graphica, 1931, p. 58.

\section{Referências bibliográficas}

AMADO, Gilberto. Eleição e representação. Rio de Janeiro: Oficina Industrial Graphica, 1931

BACKES, Ana Luiza. "Fundamentos da republicana: repensando o pacto Campos Sales". Brasília: Senado Federal, 2006.

BALANDIER, G. O poder em cena. Brasília: Editora Universidade de Brasília, 1982.

BARBOSA, Excursão eleitoral. In: Obras completas. Rio de Janeiro: Ministério da Educação e Cultura, 1967, v XXXVI.

BARRETO, V. e PAIM, A. Evolução do pensamento político brasileiro. Belo Horizonte/São Paulo: Itatiaia/Editora da USP, 1989.

DAHL, R. Poliarquia, participação e oposição. São Paulo: USP, 1997.

FILHO, Edson Benedito Rondon. Monopólio legítimo da força como processo civilizador: Weber e Elias em perspectiva. XII Simpósio Internacional, Civilização e Contemporaneidade. Recife, 2009.

HOLANDA, Cristina Buarque de. Modos de representação política. O experimento da Primeira República brasileira. Belo Horizonte: Editora UFMG; Rio de Janeiro: Editora IUPERJ, 2009

KINZO, Maria D'alva. Representação Política e Sistema Eleitoral no Brasil. São Paulo: Editor Símbolo, 1980, p. $61-132$. 
LAMOUNIER, Bolívar. Da Independência a Lula: Dois Séculos de Política Brasileira. São Paulo: Augurium Editora, Cap. 2, 2005.

LEAL, Victor Nunes. Coronelismo, Enxada e Voto. Rio de Janeiro: Forense, 1948

LESSA, R. A Invenção da República: Campos Sales, as bases e a decadência da Primeira República brasileira. Rio de Janeiro/São Paulo: IUPERJ/Vértice, 1988.

MARCHETTI, Vitor. Governança eleitoral: o modelo brasileiro de justiça eleitoral. Dados v.51 n.4 Rio de Janeiro, 2008.

NICOLAU, Jairo Marconi. Eleições no Brasil: do Império aos dias atuais. RJ: Zahar, 2012

OROZCO HENRIQUEZ, J. J. 2007. El contencioso electoral, la calificación electoral. In: NOHLEN, D.; ZOVATTO, D.; OROZCO HENRIQUEZ, J. J. \& THOMPSON, J. Tratado de derecho electoral comparado de América Latina. Ciudad del México: Fondo de Cultura Económica

PORTO, Walter Costa. A mentira da urna. São Paulo: Martins Fontes, 2004.

RICCI, Paolo. ZULINI, Jaqueline Porto. Quem ganhou as eleições? A validação dos resultados antes da criação da justiça eleitoral recebido em 13 de setembro de 2012. Revista Sociologia e Política. Curitiba, v. 21, n. 45, p. 91-105, mar. 2013

SCHUMPETER, J. A. Capitalismo, socialismo e democracia. São Paulo: Abril Cultural. 1988.

SOUZA, Maria do Carmo Campello. O Processo Político Partidário na Primeira República, 1974.

VALE, Teresa Cristina de Souza Cardoso. Justiça Eleitoral e Judicialização da Política: Um estudo através da sua história. Tese Doutorado, Instituto Universitário de Pesquisa do Rio de Janeiro. Rio de Janeiro, 2009.

VIANA, Oliveira. O idealismo da Constituição. São Paulo: Nacional, 1930 